Cite this: RSC Advances, 2013, 3, 15263

Received 8th April 2013,

Accepted 12th June 2013

DOI: $10.1039 / \mathrm{c} 3 \mathrm{ra} 41688 \mathrm{~g}$

www.rsc.org/advances

\title{
Synthesis of inorganic aerogels via rapid gelation using chloride precursors $\uparrow$
}

\author{
Helmut Schäfer, ${ }^{* a}$ Barbara Milow ${ }^{b}$ and Lorenz Ratke*b
}

\begin{abstract}
This paper describes the synthesis of silica, titania, zirconia and mixed-metal-oxide aerogels by a new facile approach. The corresponding low cost and non-toxic chlorides instead of the well established but more expensive and deleterious alkoxy precursors were used as starting materials. Hydrolysis of the precursors led to wet gels. The strong exothermic reaction in the case of $\mathrm{TiCl}_{4}$ or $\mathrm{SiCl}_{4}$ as a gel precursor can be controlled by both cooling and immersing the needle of the syringe in the aqueous solution. Under optimal conditions a rapid formation of silica- and zirconia based hydrogels could be achieved even without additional amounts of an auxiliary agent. It is shown that in all other cases the hydrolysis reaction and gel formation can be controlled by adding agents with crosslinking properties like propylene oxide, dilution with alcohols or starting from water glass. Water glass not only has the function of a cheap network former but also allows the strict adjustment of the $\mathrm{pH}$ value via neutralization of the acid forming hydrolysis reactions. Supercritical drying of the wet alkogel in $\mathrm{CO}_{2}$ delivered aerogels with BET surfaces up to $1390 \mathrm{~m}^{2} \mathrm{~g}^{-1}$, as determined by nitrogen adsorption measurements. In addition, the characterization includes XRD and SEM. These findings provide new physical insights into the hydrolysis of the gel precursors and lead to a significant reduction in production costs of inorganic aerogels.
\end{abstract}

\section{A Introduction}

Aerogels are highly porous materials with interesting properties including high specific surface area, extremely low density, low thermal conductivity and high thermal stability. ${ }^{1-5}$ Already more than 80 years back Kistler prepared the first aerogel, namely a silica aerogel by supercritical drying of silica jelly. ${ }^{6}$ Due to their unique properties aerogels are already used for a wide range of applications, including optical ${ }^{7-12}$ and electrical sensing, ${ }^{13,14}$ catalysis, ${ }^{15-17}$ as well as thermal ${ }^{18,19}$ and acoustic insulations. ${ }^{20,21}$

The alkoxide route, characterized by sol-gel transition via hydrolysis and condensation reactions of metal-, semimetal- or non-metal-alkoxide precursors such as tetraethoxysilane (TEOS), ${ }^{22-24}$ tetramethoxysilane(TMOS), ${ }^{24-27,30}$ polyethoxydisiloxane (PEDS) $)^{24}$ in the case of silica aerogels, zirconium $n$-propoxide, ${ }^{28,29}$ zirconium $i$-propoxide, ${ }^{30}$ or zirconium $n$-butoxide $^{31}$ in the case of zirconia aerogels and titanium $n$-butoxide, ${ }^{27,32,33}$ titanium $i$-propoxide, ${ }^{27,34}$ in the case of

\footnotetext{
${ }^{a}$ University of Osnabrck, Institute of Chemistry of New Materials, Physical Chemistry, Barbarastraße 7, 49069 Osnabrück, Germany.E-mail: helmut.schaefer@uos.de ${ }^{b}$ German Aerospace Center, Institute of Materials Physics in Space, Linder Höhe, 51147 Cologne, Germany. E-mail: lorenz.ratke@dlr.de

$\dagger$ Electronic supplementary information (ESI) available: Details of the synthesis procedures, additional results from nitrogen adsorption measurements as well as from powder diffraction analyses can be taken from the supporting information. This material is available free of charge via the internet. See DOI: $10.1039 / \mathrm{c} 3 \mathrm{ra} 41688 \mathrm{~g}$
}

titania aerogels, presents a common synthesis route for achieving high quality aerogels. These precursors have some drawbacks as they are costly, toxic, and depending on the nature of the alkoxy precursor and the hydrolysis conditions they can cause large gelation times up to a tenth of an hour. ${ }^{28,29,31,35}$ Furthermore, careful handling of the watersensitive compounds to prevent partial hydrolysis prior to the desired hydrolysis reaction is required. ${ }^{36-38}$ These drawbacks limit the scale-up of the synthesis procedures and pose a constraint on the use of these materials in fields where large amounts of relatively cheap materials are required (aerogelic binders, aerogel granules, foundry sand and as thermal insulating compounds in vehicles, pipelines, packaging and home building). Especially for large scale preparation of high quality aerogels the inorganic salt based synthesis routes are still challenging. Only in the case of silica aerogels a costeffective and fast synthesis procedure could be developed by using water-glass instead of a TEOS or TMOS precursor. ${ }^{39}$ In comparison with silica aerogels for instance zirconia aerogels show even slightly better properties with respect to thermal conductivity ${ }^{40}$ or melting point. ${ }^{41}$

Many papers have been published dealing with the synthesis of aerogels via the alkoxide route whereas only a small number of papers are related to the use of inorganic salts for example as zirconium sources for the synthesis of zirconia aerogels.

Chen and Jiao reported in 2007 the generation of zirconia aerogels by electrolyzing $\mathrm{ZrOCl}_{2}$ solution followed by super- 
critical drying of the so formed gel. ${ }^{42}$ The groups of A. E. Gash, ${ }^{36,43-46}$ L. J. Hope-weeks, ${ }^{4,48}$ B. Zhou, ${ }^{49}$ K. Nakanishi et al. ${ }^{50-52}$ have done plenty of work regarding the development and investigation of synthesis procedures leading to diverse oxide aerogels by using inorganic salt and additional epoxide as precursor. Anyway chloride-derived silica, titania or zirconia aerogels were rarely reported. Already more than 10 years ago Gash et al. reported on the successful generation of a chromia aerogel starting from nitrates or chlorides. ${ }^{43}$ The general suitability of the described synthesis strategy in order to synthesize other transition metal oxide aerogels was mentioned in the paper, but only the synthesis and the properties of the corresponding chromia aerogels were shown. Because of the toxic properties of chromium in its hexavalent state engineers generally try to avoid the element chromium. ${ }^{53}$

The work described in this contribution aims on the development of synthesis procedures for silica-, titania- and zirconia-aerogels, as well as mixed-metal-oxide aerogels based on cheap and non-toxic chloride based sources ${ }^{54}$ or water glass, characterized by a rapid gel-formation. Via hydrolyses of $\mathrm{TiCl}_{4}$ titania aerogels could be achieved. Titanium tetrachloride is an important intermediate in the production of titanium metal and the pigment titanium dioxide. ${ }^{55-57}$ On the basis of the bulk FOB (free on board) price of 1900 \$ per ton (99.9\% purity), ${ }^{58}$ it can be considered as one of the cheapest titanium sources. The price of titanium alkoxides of this purity is at least five times higher. ${ }^{59}$ To the best of our knowledge, up to now no aerogels were synthesized using $\mathrm{TiCl}_{4}$ as a starting material. Titania particles ${ }^{60-63}$ showing different particle sizes or coatings ${ }^{64}$ have been achieved by sol-gel approaches using $\mathrm{TiCl}_{4}$.

We show that zirconia aerogels are accessible upon hydrolysis reaction starting from the corresponding chloride salt $\mathrm{ZrCl}_{4}$, a compound which can also be considered as cheap with a bulk FOB price of $11 \mathrm{~S} \mathrm{~kg}^{-1} \cdot{ }^{65}$ No reference could be found up to now confirming the usage of this compound in order to generate pure zirconia aerogel. Where useful, water glass was inserted in our synthesis strategy. Water glass is a common network former for the generation of silica gels and aerogels. As water-glass is an economical basic chemical, an industrial process based on this precursor was developed for some time by BASF. ${ }^{66}$ Zirconia aerogels were so far achieved by using other starting materials, respectively $\mathrm{ZrCl}_{4}$ was used for other purposes: via sol-gel synthesis $\mathrm{ZrO}_{2}$ aerogel was gained starting from $\mathrm{Zr}_{3}\left(\mathrm{PO}_{4}\right)_{4} \cdot{ }^{67}$ Kauzlarich et al. synthesized yttriastabilized zirconia by a non-alkoxide sol-gel route via hydrolysis of $\mathrm{ZrCl}_{4}$ and $\mathrm{YCl}_{3} \cdot{ }^{36}$ Richards et al. showed that iron-doped zirconia aerogels can be achieved by using zirconyl nitrate and iron nitrate as zirconium, respectively iron precursors via a solvothermal approach. ${ }^{68}$ Different high vacuum technologies like chemical vapour deposition (CVD), ${ }^{69}$ atomic layer deposition (ALD), ${ }^{70,71}$ and atomic layer chemical vapor deposition (ALCVD) ${ }^{72}$ have been used to generate zirconia thin films starting from $\mathrm{ZrCl}_{4}$.

We achieved mixed silica-titania aerogels through the reaction of water glass with $\mathrm{TiCl}_{4}$ whereas in the literature only the alkoxy route for the generation of theses compounds (based on a mixture of Si- and Ti-alkoxides ${ }^{4,73,74}$ or single source alkoxy precursors ${ }^{75-77}$ ) could be found. With respect to titania-zirconia aerogels, no reports in the literature could be found, indicating the access of this mixed oxide aerogels by using titanium and zirconium chlorides. Wang et al. reported in 2005 on the synthesis of titania-zirconia composite particles by a solvothermal procedure in an alcoholic solution at elevated temperatures involving chloride salts. ${ }^{78}$ Only one paper reported on the synthesis of this composite aerogel starting from titanium-zirconium salts $\left(\mathrm{Ti}\left(\mathrm{SO}_{4}\right)_{2}\right.$ and $\left.\mathrm{ZrOCl}_{2}\right)$. The properties, especially the specific surface area with a value of $387 \mathrm{~m}^{2} \mathrm{~g}^{-1}$ at intensive heat treatment, were not satisfying. ${ }^{79}$ The alternative synthesis routes presented herein not only allow the reduction in the synthesis cost and the improvement in the scalability of the procedures, but also enable fine-tuning of the materials properties such as pore structure, constitution and density of the aerogels.

\section{B Experimental methods}

\section{B1 Reagents}

Zirconium(Iv) chloride (99.5\%, Aldrich), silicium(Iv) chloride (99\%, Aldrich), propylene oxide (99\%, Aldrich), titanium(IV) chloride (98\%, Fluka) and water glass (1.39 $\mathrm{g} \mathrm{cm}^{-3}$, Aldrich) were used as received unless noted otherwise. The synthesized aerogel samples were sputtered with gold and the morphology of the aerogels was investigated with a scanning electron microscope LEO 1530 VP. For this purpose non treated aerogel bodies as well as sliced aerogel bodies were used. Powder diffraction analyses were performed with an X'Pert Pro Diffractometer (Panalytical). The as-prepared aerogels were mortared and the X-ray diffraction data were recorded in order to determine the crystallographic phase. Afterwards the samples were heated up to $450{ }^{\circ} \mathrm{C}$ in a standard oven (Naber $\mathrm{N}$ 11) under air and the crystallographic data were measured again. The surface area, pore size and pore size distribution were measured by using a multiple point nitrogen gas adsorption BET surface area analyzer (Micromeritics Tristar). Before the aerogel samples were de-gassed at $120{ }^{\circ} \mathrm{C}$ for 30 $\min$.

Pore size distributions were calculated from the desorption isotherms using the $\mathrm{BJH}$ method.

\section{B2 Processing}

B2.1 Synthesis of the hydrogels (Scheme 1). In a typical synthetic procedure a $20 \mathrm{ml}$ plastic beaker was filled with distilled water, water/alcohol respectively water/tetrahydrofuran (THF) mixtures. The constitution of the solvent mixtures can be taken from Tables TS1-TS4, ESI $\dagger$ (supporting information). The metal salt was slowly added under stirring using a magnetic stirrer. In all cases the heat-release was compensated via a water bath (to $20{ }^{\circ} \mathrm{C}$ ) and the stirring speed was adjusted to $700 \mathrm{rpm}$. Within $90 \mathrm{~s}$ addition of the chloride precursor was completed. $\mathrm{ZrCl}_{4}$ was slowly added in small portions using a spatula. $\mathrm{SiCl}_{4}$, and $\mathrm{TiCl}_{4}$ were added via a syringe. It has 


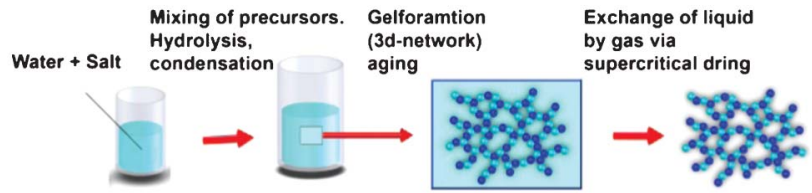

Scheme 1 Schematic presentation of the synthesis procedure.

proven effective to immerse the front tip of the needle of the syringe in the aqueous solution prior to the addition of the compounds in order to avoid any splashing due to the highly exothermic reaction. Immediately thereafter the auxiliary agent was added, which was found to be a requirement for the generation of titania or zirconia gels and some mixed metal oxide gels (Tables TS2-TS4, ESI $\dagger$, supporting information). In case of the water glass assisted gel formation (Table TS4, ESI†), diluted water glass was filled into the beaker prior to the addition of the metal oxide precursor. In two cases water glass was replaced by the alkaline compound $\mathrm{NaOH}$ (Table TS4, ESI $\dagger$ ) which was added after addition of the chloride precursor prior to gel formation. The solution was vigorously stirred until gel formation occurred at a $\mathrm{pH}$ value of around 5 . The gel was aged with ethanol for around one week. Residual salts like $\mathrm{NaCl}$ and other byproducts like chloropropanol were washed out with water. Details of the synthesis procedures including the amounts of solvent, metal oxide precursor, auxiliary agent, alkaline component and the gelation times and can be taken from Tables TS1-TS4, ESI†. The gel time was defined as the time passed between additions of the last component required for the sol-gel transition and the disappearance of the vortex created by the rotating stirring bar.

B2.2 Synthesis of the aerogels. After solvent exchange with ethanol (20 $\mathrm{ml}$ for each sample) the wet gels were supercritically dried with carbon dioxide. Therefore the wet gels were transferred into a special metal shell (Fig. 1a), which was filled with ethanol. For this a knife was stuck through the bottom of the plastic beaker and thereby the gel body was carefully pushed out of the beaker. During this procedure it was ensured that the gel body has had no contact to air i.e. no phase boundary has penetrated the body. The shell was put into a DLR (German Aerospace Center, Deutsches Zentrum für Luft- und Raumfahrt)-made autoclave (Fig. 1b), which was tempered with cooling water of $17{ }^{\circ} \mathrm{C}$. The autoclave was closed and afterwards liquid carbon dioxide was flushed into the autoclave until around $3 \mathrm{~cm}$ above the upper border of the shell. After a while the valve was opened and the fluid level was reduced down to $0.5 \mathrm{~cm}$ above the upper border of the shell. By this means ethanol was exchanged by $\mathrm{CO}_{2}$ and the samples were flushed 10 times per day over a period of 2 days until the escaping $\mathrm{CO}_{2}$ did not contain any more traces of ethanol. Afterwards the temperature was increased above the critical point $\left(31.1{ }^{\circ} \mathrm{C} ; 73.8\right.$ bar). At around $40{ }^{\circ} \mathrm{C}$ and 90 bar supercritical conditions were reached, i.e. the phase boundary disappeared. Via slow depressurization in most cases crack free aerogel bodies were gained (see Fig. 1a). Photos of crushed aerogel bodies gained after supercritical drying can be taken from S15-S28, ESI $\dagger$ (supporting information).
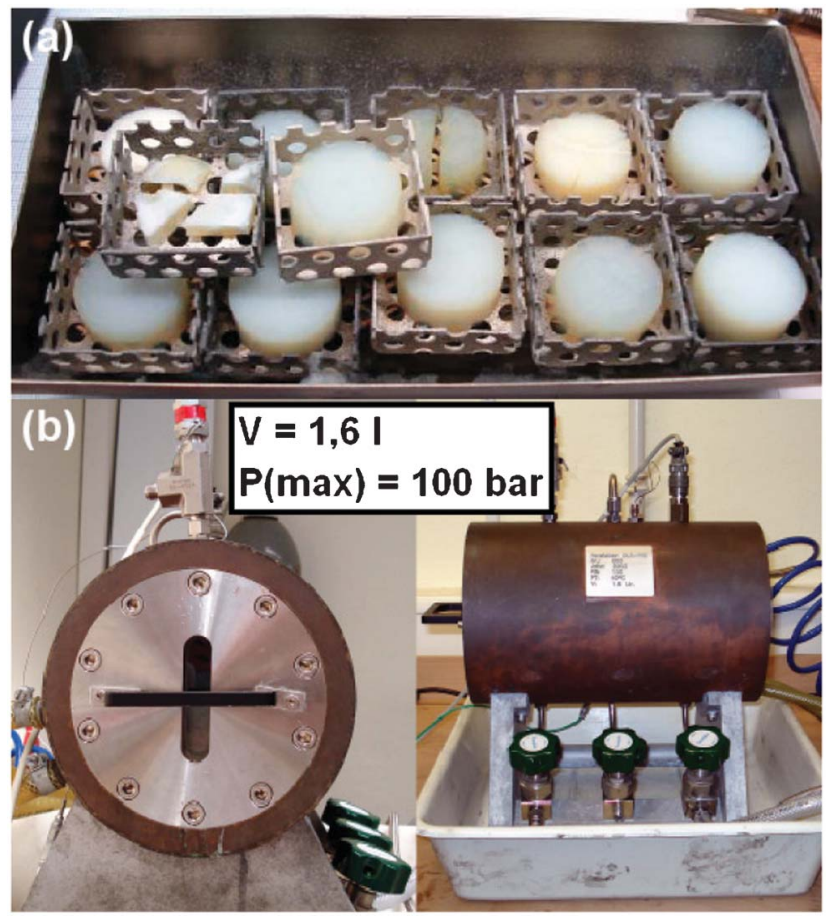

Fig. 1 (a) Metal shell with aerogels (HS_33) after supercritical drying. (b) DLRmade autoclave for supercritical drying.

\section{Results and discussion}

\section{C1 Synthesis of the aerogels}

Silicon-, titanium- and zirconium oxide aerogels are among the most common aerogels due to their sophisticated properties like thermal stability, ${ }^{41,79}$ photocatalytic properties, ${ }^{80-82}$ in general low density, ${ }^{1}$ high acoustical and thermal insulating properties. ${ }^{1}$ Therefore we started our investigations with finding alternative precursors and overall facile approaches allowing to access these aerogels as well as mixed metal oxide aerogels containing two of the elements $\mathrm{Si}$, Ti, and $\mathrm{Zr}$. As Tables TS1-TS4, ESI $\dagger$ show, provided that suitable reaction conditions (constitution and temperature of the reaction mixture, $\mathrm{pH}$ value, stirrer speed and time duration for adding the precursors) have been chosen, abrupt gel-formation takes place. All the gels presented in the tables could be transferred to aerogels via supercritical drying in $\mathrm{CO}_{2}$.

We were successful in preparing silica aerogels starting from $\mathrm{SiCl}_{4}$ plus water or water THF mixtures, silica aerogels starting from $\mathrm{SiCl}_{4}$ plus water glass, titania aerogels starting from $\mathrm{TiCl}_{4}$ plus water or water/alcohol mixtures, zirconia aerogels starting from $\mathrm{ZrCl}_{4}$ plus water and zirconia-titania, silica-titania mixed metal oxide aerogels starting from the corresponding chlorides via reaction with water or water glass with or without propylene oxide as auxiliary agent. In most of the cases a sol gel transition occurs within seconds (see Fig. 2, 4, 5, 6). From alkoxy precursors it is known, that they, depending on reaction conditions and type of the precursors, require gelling times up to a tenth of an hour. ${ }^{24,28,29,31,35,96}$ Especially for silica aerogels long gelling times go along with low transmittance. ${ }^{83}$ Series 
(a)

\begin{tabular}{|l|c|}
\hline $\begin{array}{l}\text { Sample } \\
\text { name }\end{array}$ & BET $\left(\mathbf{m}^{2} / \mathbf{g}\right)$ \\
\hline HS_16.2 & 450 \\
\hline HS_36 & 1391 \\
\hline HS_8 & 459 \\
\hline HS_97 & 616 \\
\hline HS_128 & 733 \\
\hline HS_129 & 460 \\
\hline
\end{tabular}

(b)

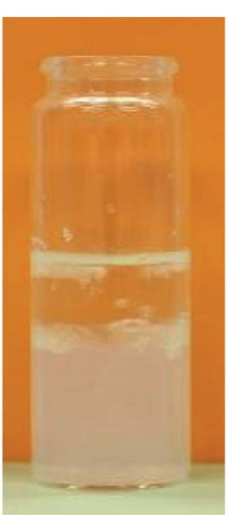

Fig. 2 (a) BET surface area for silica aerogels. (b) Image of sol-gel transition of $\mathrm{SiCl}_{4}$ containing reaction mixture (sample HS_16.2).

syntheses show beyond that the gelling time is well reproducible. Supported not only by our findings it must be mentioned that the use of water glass up to some extent impairs the repeatability especially with respect to gelling time or overall gelation behaviour. ${ }^{84,85}$ Slight differences in the composition of water glass might be one reason. We obtained that e.g. the sodium content differs from supplier to supplier and hence commercially available sodium silicate solutions show $\mathrm{Na}_{2} \mathrm{O}$ concentrations with values between 8 and $14 \mathrm{wt} . \%$. Even when purchased from one supplier the composition can vary and the $\mathrm{Na}_{2} \mathrm{O}$ content can reach values between 8.3 and 13 wt.\%, respectively the $\mathrm{SiO}_{2}$ content can be in the range between 26.5 and 29 wt.\%. ${ }^{86}$ This makes it difficult to design a reliable synthesis route. It turned out that in case that water glass was inserted in the reaction mixture abrupt gelformation could be realized by adjusting the $\mathrm{pH}$ value in the range of 3. Depending on the ratio of alkaline compounds to acidic compounds i. e. the ratio of water glass to $\mathrm{TiCl}_{4}$, respectively the ratio of water glass to $\mathrm{SiCl}_{4}$, the $\mathrm{pH}$ value was controlled by adding either $\mathrm{HCl}$ or $\mathrm{NaOH}$. From literature is
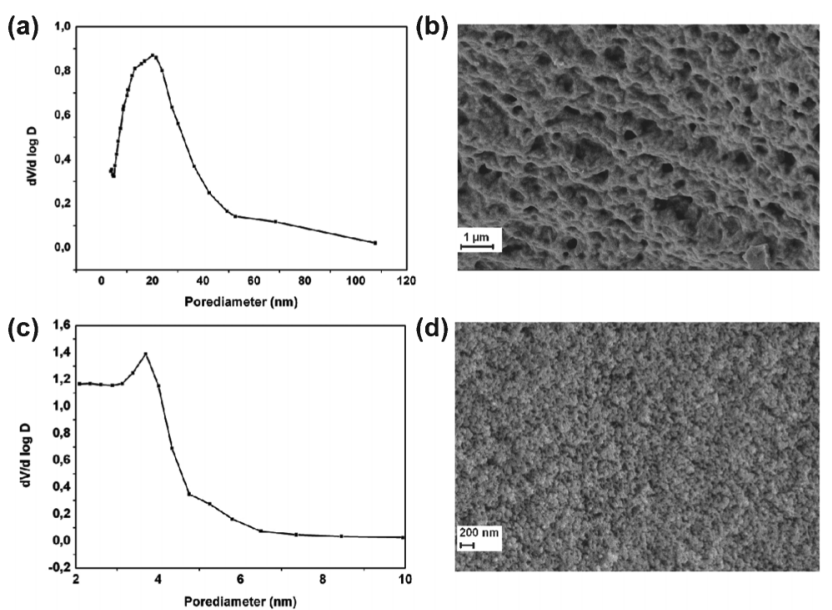

Fig. 3 BJH plot from silica aerogel sample HS_16.2 (a) and sample HS_36 (c). SEM pictures of silica aerogel sample HS_16.2 (b) and sample HS_8 (d). known that for the generation of microporous silica aerogels starting from water glass a pH value in between 3 and 5 seems to be desirable. ${ }^{87-89}$

Supercritical drying with $\mathrm{CO}_{2}$ was found to be the method of choice for the replacement of liquid by gas in the pores of the generated gels in order to achieve aerogels of high quality. The elsewhere reported long diffusion time and hence, time consuming solvent exchange between solvent and $\mathrm{CO}_{2}{ }^{90}$ could not be confirmed by us. The complete drying procedure using supercritical $\mathrm{CO}_{2}$ was completed within $48 \mathrm{~h}$. In general the supercritical drying procedure was more and more optimized over a long time period by different groups ${ }^{91}$ i.e. the statement that this drying technique is inefficient, expensive and not scaleable ${ }^{92}$ is more than questionable. $\mathrm{CO}_{2}$ technology is already commercially applied in a variety of fields - from pharmacy to food sciences to the textile industry. $\mathrm{CO}_{2}$ can be recycled easily, it is also non-flammable, non-toxic and inexpensive. ${ }^{93}$ In many cases the process costs are lower than comparable conventional processes. ${ }^{93}$ In comparison with other media used within the supercritical drying procedure like acetone ${ }^{94}$ or alcohols, ${ }^{80,95,96} \mathrm{CO}_{2}$ benefits from its relatively mild supercritical conditions, especially the low supercritical temperature of $304.13 \mathrm{~K}$. With the help of water glass, aerogels consisting of silica-titania mixed metal oxide aerogels were accessible even without additional auxiliary agent like propylene oxide (see Table TS4, ESI + ). In all other cases propylene oxide acts, as a proton scavenger and raises the $\mathrm{pH}$-value during the reaction. Reaction generated $\mathrm{HCl}$ is compensated, the hydrolysis and condensation can occur to form a three dimensional network. ${ }^{96}$ During the condensation reaction chloropropanol is formed and can be easily washed out with ethanol or acetone.

With this synthesis strategy the overall costs of the synthesis procedure could be kept within limits inasmuch as also the chosen auxiliary agent propylene oxide is with a FOB price of 1900 \$ per ton ${ }^{97}$ a low cost compound. At the same time acceptable results could be obtained. Detailed information can be taken from Fig. 2-6, TS1-TS4, ESI (supporting information) showing the constitution of the reaction mixtures, surface area, pore size distributions (BJH plots), the XRD powder pattern and SEM images.

\section{C2 Properties of the aerogels}

C2.1 Silica aerogels. Two different synthesis strategies were realized in order to synthesize silica aerogels. One is based on the simple hydrolysis reaction of $\mathrm{SiCl}_{4}$ (HS_16.2, HS_36, HS_8) in water or water-THF mixtures. Alternative to this procedure the material was achieved by immersing $\mathrm{SiCl}_{4}$ into water glass (HS_97, HS_128, HS_129, see also Fig. TS2, ESI†).

For silica aerogels gained from $\mathrm{SiCl}_{4}$, BET surface values within the range 450 to almost $1400 \mathrm{~m}^{2} \mathrm{~g}^{-1}$ were obtained (Fig. 2a). The hydrolysis reaction of $\mathrm{SiCl}_{4}$ with water led, under optimal reaction conditions, to an aerogel with a surface area of $1391 \mathrm{~m}^{2} \mathrm{~g}^{-1}$ (HS_36). The gel formation took place within less than $30 \mathrm{~s}$. The corresponding white aerogel body was crack free but not transparent. The aerogel achieved by a similar synthesis route using $0.9 \mathrm{ml} \mathrm{SiCl}{ }_{4}$ instead of $1 \mathrm{ml}$ showed a drastic reduced surface area of $450 \mathrm{~m}^{2} \mathrm{~g}^{-1}$ (HS_16.2). 
(a)

\begin{tabular}{|l|c|}
\hline Sample name & $\begin{array}{c}\text { BET } \\
\left(\mathbf{m}^{2} / \mathbf{g}\right)\end{array}$ \\
\hline HS_138 & 733 \\
\hline HS_10.2 & 610 \\
\hline HS_145 & 480 \\
\hline HS_141 & 466 \\
\hline
\end{tabular}

(d)

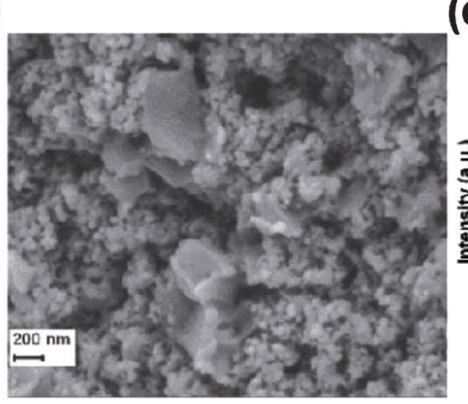

(e) (b)

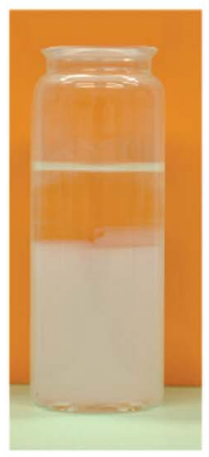

(c)

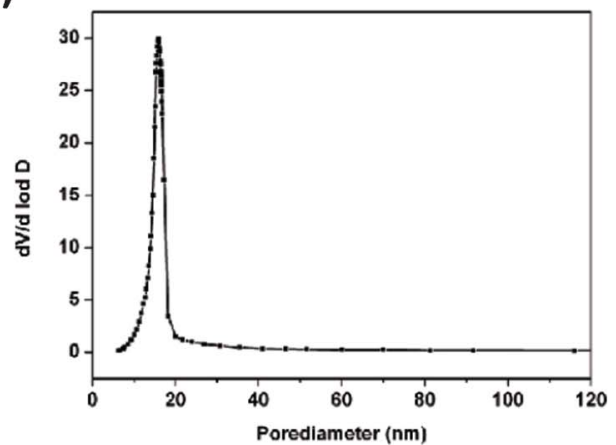

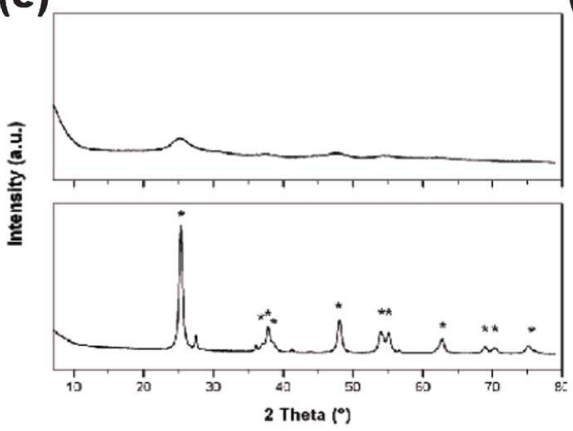

(f)

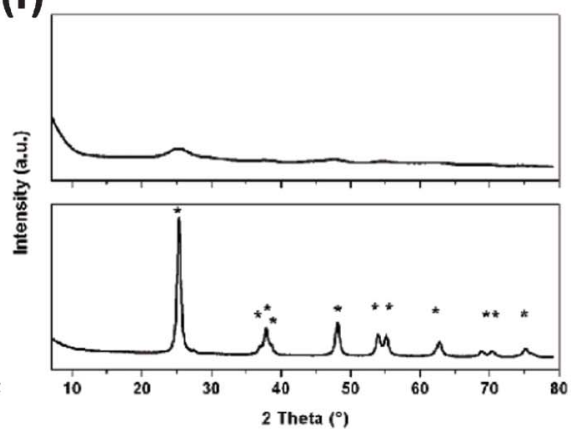

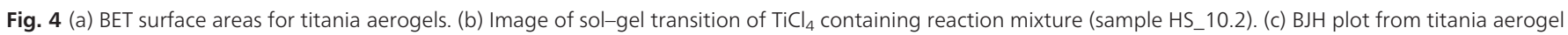

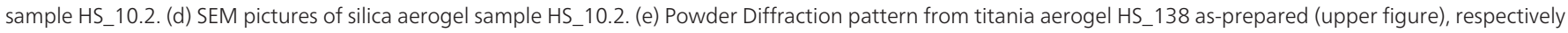
heat-treated (lower figure). Peaks corresponding to tetragonal $\mathrm{TiO}_{2}$, anatase modification (JCPDS 004-0477) are marked with an asterisk. (f) Powder diffraction pattern from titania aerogel HS_10.2 as-prepared (upper figure), respectively heat-treated (lower figure). Peaks corresponding to tetragonal TiO 2 (anatase modification) (JCPDS 004-0477) are marked with an asterisk.

The SEM image of the surface of this sample can be taken from Fig. 3b. It turned out that the hydrolysis of $\mathrm{SiCl}_{4}$ performed in a solvent mixture of water-THF led to transparent gel bodies (HS_8). However showing a BET value of $459 \mathrm{~m}^{2}$ $\mathrm{g}^{-1}$ the specific surface was much lower in comparison with our best sample. In addition the time required for gel formation was 2 days, which within this series of experiments represents the longest time. Some alkoxy precursor routes require duration times in the same dimension. Rao et al. reported on the synthesis and characterization of silica aerogels by hydrolysis reactions of TEOS, TMOS or polyethoxydisiloxane (PEDS). ${ }^{24}$ The hydrolysis of TEOS in alcohol-water mixtures delivered after 2.2 days a stable gel which could, via supercritical drying in $\mathrm{CO}_{2}$, transferred to an aerogel with a surface area of $800 \mathrm{~m}^{2} \mathrm{~g}^{-1} \cdot{ }^{24}$ By using TMOS or PEDS instead of TEOS the gelation time could be decreased down to $30 \mathrm{~min}$ (TMOS), respectively $10 \mathrm{~min}$ for PEDS and at the same time the surface area was increased to $1000 \mathrm{~m}^{2} \mathrm{~g}^{-1}$ (TMOS), respectively $1100 \mathrm{~m}^{2} \mathrm{~g}^{-1}$ (PEDS). Anyway neither the use of TEOS, nor the use of TMOS is desirable most of all because of their toxicity. ${ }^{98}$ A silica aerogel with a BET value of $733 \mathrm{~m}^{2} \mathrm{~g}^{-1}$ from the reaction of $\mathrm{SiCl}_{4}$ with water glass followed by supercritical drying could be achieved (HS_128). Unfortunately the corresponding aerogel body, white in color, showed cracks. Tamon et al. investigated silica aerogels synthesized from TEOS and reported on the relation between visible light transmittance (wavelength: $600 \mathrm{~nm}$ ) of silica aerogels and surface area. ${ }^{99}$
They found that the higher the surface area the higher the light transmittance. The possibility that the light transmittance of an aerogel body can be used as a criterion in order to

(a)
\begin{tabular}{|l|c|}
\hline Sample name & BET $\left(\mathrm{m}^{2} / \mathrm{g}\right)$ \\
\hline $1.2\left(\mathrm{HS} \_3.1\right)$ & 174 \\
\hline 1.3 a (HS_3.2) & 609 \\
\hline $1.3 \mathrm{~b}$ (HS_33) & 577 \\
\hline
\end{tabular}
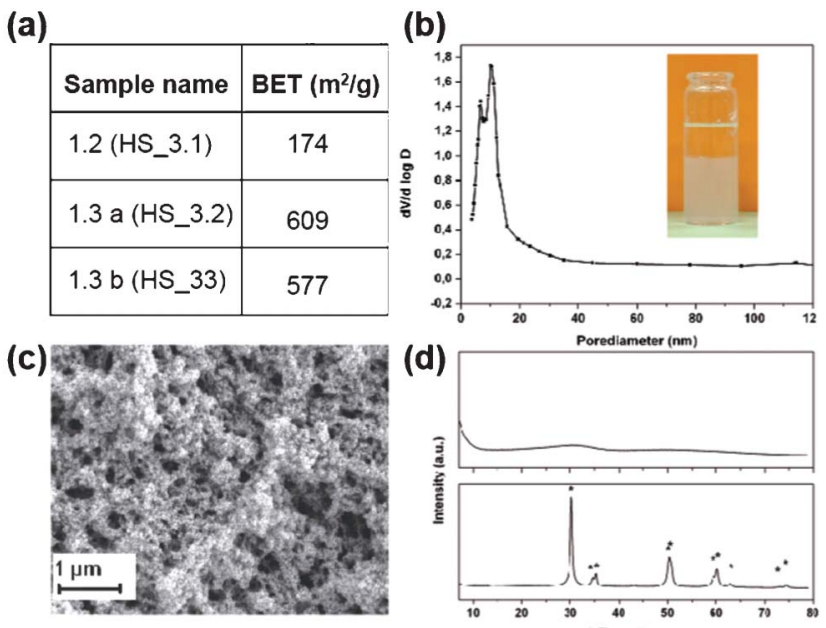

(d)

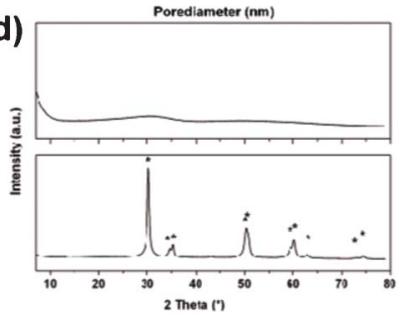

Fig. 5 (a) BET surface area for zirconia aerogels. (b) BJH plot from zirconia aerogel sample HS_3.2. The inset showing the image of sol-gel transition of $\mathrm{ZrCl}_{4}$ containing reaction mixture (sample HS_3.2). (c) SEM pictures of silica aerogel sample HS_3.2. (d) Powder diffraction pattern from zirconia aerogel HS_3.1 asprepared (upper figure), respectively heat-treated (lower figure). Peaks corresponding to tetragonal $\mathrm{ZrO}_{2}$ (JCPDS 01-080-0965) are marked with an asterisk. 
(a)

\begin{tabular}{|c|c|c|}
\hline Sample name & Metal oxide & BET $\left(\mathbf{m}^{2} / \mathbf{g}\right)$ \\
\hline HS_32 & ZrO/TiO & 577 \\
\hline HS_46 & SiO/TiO & 241 \\
\hline HS_91 & SiO/TiO & 555 \\
\hline HS_115 & SiO/TiO & 502 \\
\hline HS_121 & SiO/TiO & 385 \\
\hline HS_43.1 & SiO/TiO & 71 \\
\hline HS_123 & SiO/TiO & 372 \\
\hline HS_126 & SiO/TiO & 954 \\
\hline
\end{tabular}

(b)
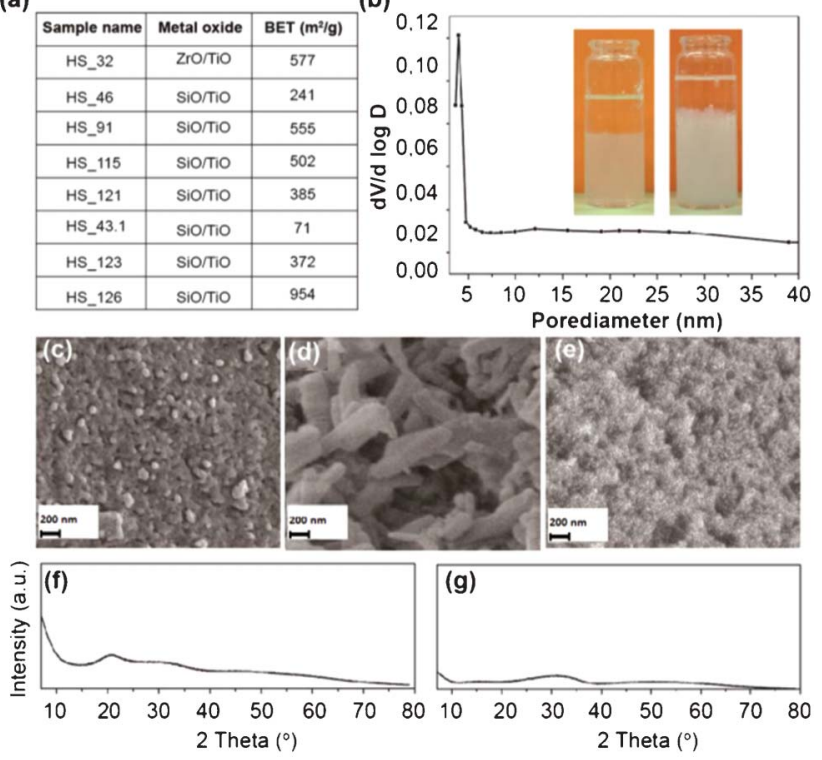

Fig. 6 (a) BET surface area for mixed metal oxide aerogels. (b) BJH plot from zirconia-/titania aerogel sample HS_32. The inset showing image of sol-gel transition of $\mathrm{ZrCl}_{4}$ and $\mathrm{TiCl}_{4}$ containing reaction mixture (sample HS_32) (left) and of $\mathrm{SiCl}_{4}$ and water glass containing reaction mixture (sample HS_97) (right). (c-e) SEM pictures of silica aerogel sample HS_32 (c), HS_43.1 (d) and HS_126 (e). $(f-g)$ Powder diffraction pattern of titania-zirconia aerogel HS_32 before ( $f$ ) and after $(\mathrm{g})$ annealing.

predict the quality e.g. the BET surface seems to be valid only within a series of syntheses with similar characteristics with respect to precursors, reaction conditions and so on. While changing the reaction parameters within the synthesis series of our silica aerogels we could not prove this generally applicable rule. For the transparent sample HS_8 (see also SEM image Fig. 3d) a BET value of $459 \mathrm{~m}^{2} \mathrm{~g}^{-1}$ was determined whereas the turbid sample HS_36 showed a surface area of almost $1400 \mathrm{~m}^{2} \mathrm{~g}^{-1}$. The pore size distributions of selected silica aerogels can be taken from the $\mathrm{BJH}$ plots shown in Fig. 3a, 3c, S1-S3, ESI†.

The samples gained from the hydrolysis of $\mathrm{SiCl}_{4}$ with water showed, although the constitution of the reaction mixture only slightly differs, large deviations with respect to the pore size distribution. When $0.9 \mathrm{ml} \mathrm{SiCl} 4$ was used (HS_16.2) a broad size distribution was found, showing pore sizes in the range 5$50 \mathrm{~nm}$ (Fig. 3a). In an equal synthesis reaction $1 \mathrm{ml}$ of the same precursor already led to very small pores below $6 \mathrm{~nm}$ and a narrow size distribution with pore sizes within the range of 2-6 nm (Sample HS_36; Fig. 3c). The reproducibility of both results was satisfying and it is actually not fully understood why small changes in the constitution of the reaction mixture has such a big influence on the results. Generally $\mathrm{SiO}_{2}$ exists in different crystalline modifications, crystalline phases like quartz, tridymite or christobalite. All as-prepared silica aerogels as well as all samples heated up to $450{ }^{\circ} \mathrm{C}$ consisted of X-ray amorphous $\mathrm{SiO}_{2}$. This can be taken from the powder diffraction pattern of selected samples (see Fig. S4-S7, ESI $\dagger$ ). In case of HS_97 the diffraction pattern show peaks belonging to $\mathrm{NaCl}$, JCPDS 01-077-2064 (see Fig. S7, ESI $\dagger$ ). $\mathrm{NaCl}$ is a byproduct from the reaction of water glass and $\mathrm{SiCl}_{4}$. Before heat treatment the samples were washed with water to remove impurities coming from precursors or byproducts like $\mathrm{NaCl}$. This is the reason that only traces of $\mathrm{NaCl}$ can be found in the heat treated sample (see Fig. S7, ESI $\dagger$ ).

Hydrolysis of $\mathrm{SiCl}_{4}$ performed in $\mathrm{H}_{2} \mathrm{O}$ /THF mixtures followed by drying of the gels resulted in an aerogel with a pore size distribution of 3-23 nm (sample HS_8, Fig. S1, ESI $\dagger$ ). A very broad range of pore sizes could be found for the aerogels derived from $\mathrm{SiCl}_{4}$ and water glass (samples HS_97, HS_128; Fig. S2, S3, ESI $\dagger$ ).

C2.2 Titania aerogels. Fig. 4a shows the surface area of the titania aerogels we achieved using $\mathrm{TiCl}_{4}$ as titanium precursor. Fig. 4c shows the BJH plot of a selected titania aerogel (HS_10.2). Within the synthesis series the amount of $\mathrm{TiCl}_{4}$ was kept fixed. It turned out that changes within the constitution of the solvent (water or water-ethanol mixtures) or the concentration of the auxiliary agent propylene oxide had only an effect on the surface area of the corresponding aerogel but not on the pore sizes respectively the pore size distributions. We obtained, depending on the constitution of the reaction mixture, surface areas in between 466 and $733 \mathrm{~m}^{2} \mathrm{~g}^{-1}$. All (titania) samples showed almost the same pore size distribution with pore sizes within a narrow range between 10 and 20 $\mathrm{nm}$ (see Fig. 4c). The SEM analysis of a sectional area of sample HS_10.2 can be taken from (Fig. 4d). Although big pores in a range $\gg 100 \mathrm{~nm}$ were obtained, the total number of these bigger cavities in comparison with the total number of small pores $<20 \mathrm{~nm}$ seems to be negligibly small (see BJH plot Fig. 4c). BJH plots on the basis of BET measurements only take the open porosity into account which does not contribute to the skeletal density. In the case of HS_10.2 the bigger pores seem to be not connected to other pores i.e. not contribute to what we see via BET measurements. Titanium dioxide crystallizes in three different crystal forms at atmospheric pressure: anatase, brookite and rutile. The as-prepared titania aerogels were X-ray amorphous as can be taken from Fig. 11, 12. The heat treated samples were crystalline showing the tetragonal anatase-phase, JCPDS 004-0477, (see Fig. 4e, f). This finding is not astonishing. The gas phase hydrolysis of $\mathrm{TiCl}_{4}$ performed at $360-550{ }^{\circ} \mathrm{C}$ by Xia et al. also led to anatase-phase $\mathrm{TiO}_{2} \cdot{ }^{60,100}$ Ko et al. found that rutile type $\mathrm{TiO}_{2}$ only begins to form at 873 $\mathrm{K}$ and is than the dominant phase at $1073 \mathrm{~K}^{32}$ Crystalline titania aerogels showing the anatase form right after supercritical drying in alcohol-water mixtures at $300{ }^{\circ} \mathrm{C}$ were achieved by Brown et al. ${ }^{27}$

Recently Anderson et al. reported on the synthesis of titania and mixed silica-/titania aerogels using autoclave technique in which both, gelation of the alkoxy precursors and supercritical drying was performed. ${ }^{27}$ The advantage of this method is that it is less time consuming ( $<6 \mathrm{~h}$ in total) than the classical solgel procedure. This synthesis procedure, developed by Gauthier et al. $^{101}$ led to titania aerogels with surface areas in the range between 127 and $188 \mathrm{~m}^{2} \mathrm{~g}^{-127}$ so much lower than the ones we generated starting from inorganic chlorides. Small surface areas of around $220 \mathrm{~m}^{2} \mathrm{~g}^{-1}$ for titania aerogels were also reported by Ko et $a l^{32}$ The aerogels were gained from classical synthesis procedures starting from titanium $n$-butoxide via sol-gel transition. Photocatalytic properties of titania 
based composite aerogels achieved from the alkoxy synthesis route were described in a recent publication written by Sunol et $a .^{33}$ They compared their products with commercially available industry standard $\mathrm{TiO}_{2}$ compounds and found 5-10 times greater BET surface areas. Anyway the BET values obtained here were at least $50 \%$ lower in comparison with our findings.

C2.3 Zirconia aerogels. Fig. 5a shows the surface areas of our zirconia aerogel samples. We found out that the hydrolysis and condensation of $5 \mathrm{mmol} \mathrm{ZrCl}_{4}$ can ideally be performed in $10 \mathrm{ml}$ water and $5 \mathrm{ml}$ propylene oxide leading to aerogels with surface areas of about $600 \mathrm{~m}^{2} \mathrm{~g}^{-1}$ (HS_3.2). This exactly matches the surface size of the corresponding titania compound HS_10.2 derived from an equal reaction mixture ( $5 \mathrm{mmol} \mathrm{TiCl}_{4}$ instead of $\mathrm{ZrCl}_{4}$, see Table TS2, ESI $\dagger$ ). The BJH plot (Fig. 5b) of sample HS_3.2 is comparable to the one obtained for the corresponding titania aerogel HS_10.2 as well (Fig. 4c). Also here a narrow pore size distribution is shown, presenting pore sizes in the range between 3 and $20 \mathrm{~nm}$. Fig. 5c shows the SEM image of sample HS_3.2. Also here on different areas of sliced pieces of the aerogel body bigger pores in the range between 200 and $1000 \mathrm{~nm}$ than the ones "visible" via BET analyses can be detected. $\mathrm{ZrO}_{2}$ is found with different crystal structures. Known are the monoclinic (baddeleyite), a tetragonal and a cubic modification (fluorite type). Also the non heat treated zirconia aerogels show no crystallinity as can be derived from the X-ray powder diffraction pattern of sample HS_3.1 (Fig. 5d upper image). Whereas the samples heated to $450{ }^{\circ} \mathrm{C}$ crystallize in the tetragonal structure (JCPDS 01-0800965) as can be taken from Fig. 5d lower image. Upon calcination at $773 \mathrm{~K}$ Baiker et al. obtained tetragonal phase zirconia as well. ${ }^{31}$ The temperature depending tetragonal to monoclinic phase transition of zirconia aerogels was investigated by Ko et $a l .{ }^{28}$ who found at $773 \mathrm{~K}$ also monoclinic phase zirconia after heating for a day or more.

In comparison with synthesis procedures leading to titania aerogels which are actually all based on organic precursors, in case of zirconia aerogels some synthesis routes starting from inorganic precursors are described in the literature. Most of the synthesis procedures leading to zirconia aerogels reported so far are based on tetra alkoxy precursors like zirconium tetra$n$-propoxide, ${ }^{28,29}$ zirconium tetra- $i$-propoxide, ${ }^{30}$ and zirconium tetra- $n$-butoxide. ${ }^{31}$

Ko et al. reported on the syntheses of zirconia aerogels starting from both, inorganic and organic $\mathrm{Zr}$ precursors ${ }^{28}$ and studied the effect of heat treatment on the physical properties of this material achieved from zirconium- $n$-propoxide. He obtained BET surface areas up to $134 \mathrm{~m}^{2} \mathrm{~g}^{-1}$ and mentioned in his report other groups who performed hydrolysis reactions of zirconyl chloride and zirconyl nitrate at last resulting in aerogels with surface areas in the same range. By using the same precursor (zirconium- $n$-propoxide) Suh et al. obtained slightly higher BET values and studied the effect of the reaction temperature on the gelation time as well as the influence of the aging conditions on the textural properties. ${ }^{29}$ Baiker published on the synthesis and characterization of zirconia aerogels starting from the hydrolysis of zirconium tetra butoxide in acid-alcohol mixtures. ${ }^{31}$ They obtained, depending on the nature of supercritical drying $\left(\mathrm{CO}_{2}\right.$ low temperature or alcohol high temperature drying condition), BET values in the range 50-100 for $\mathrm{CO}_{2}$ dried species and 140$200 \mathrm{~m}^{2} \mathrm{~g}^{-1}$ for the high temperature dried aerogels. ${ }^{31}$ Surface areas in the range we found for zirconia aerogels were published by Hui et al. in a recent publication. ${ }^{102}$ Hydrolysis and condensation of zirconium nitrate with the help of propylene oxide followed by ambient pressure drying resulted in aerogels with nanoscale porous network showing pore sizes below $10 \mathrm{~nm}$ and surface areas in between 480 and $650 \mathrm{~m}^{2} \mathrm{~g}^{-1}$ whereas all procedures starting from organic zirconium precursors seem to result in aerogels with lower surface areas showing values in the range between 50 and $240 \mathrm{~m}^{2}$ $\mathrm{g}^{-1} \cdot 28,29,31,103$

C2.4 Mixed metal oxide aerogels. The surface areas of the mixed metal oxide aerogels can be taken from Fig. 6a. Fig. 6b, S8-S10, ESI $\dagger$ show the BJH plots from selected samples of zirconia-titania and silica-titania aerogels. Zirconia-titania aerogels were achieved by immersing equal ( $5 \mathrm{mmol}$ ) amounts of $\mathrm{ZrCl}_{4}$ and $\mathrm{TiCl}_{4}$ into water-propylene oxide mixtures followed by supercritical drying of the gel. Small pore sizes and a narrow pore size distribution $(2-5 \mathrm{~nm})$ can be taken from the BJH plot (Fig. 6b) of sample HS_32. The surface area is $577 \mathrm{~m}^{2} \mathrm{~g}^{-1}$. The SEM image (Fig. 6c) shows a smoother surface. Pores with sizes $>100 \mathrm{~nm}$ could not be found in any area. In contrary to the successful synthesis described so far a mixture of $\mathrm{ZrCl}_{4}$ and sodium silicate solution resulted in nonstable wet gels. The powder diffraction analyses of sample HS_32 which can be taken from Fig. 6f and $\mathrm{g}$ show an interesting result. Neither the as-prepared compound, nor the heat treated $\left(450{ }^{\circ} \mathrm{C}\right)$ compound shows crystallinity. At relatively low temperature Wang and Xiao generated crystalline nanocomposite particles consisting of anatase-type titania $\left(\mathrm{TiO}_{2}\right)$ and cubic/tetragonal zirconia via hydrolysis reaction of $\mathrm{TiCl}_{4}$ and $\mathrm{ZrOCl}_{2}{ }^{78}$

Titania-zirconia composite aerogel materials have been prepared by sol-gel transition of the hydrolysis reaction of inorganic precursors $\mathrm{Ti}\left(\mathrm{SO}_{4}\right)_{2}$ and $\mathrm{ZrOCl}_{2}$ plus subsequent supercritical drying in $\mathrm{CO}_{2} \cdot{ }^{79}$ This is indeed an interesting approach. The aerogels showed depending on the $\mathrm{TiO}_{2}$ to $\mathrm{ZrO}_{2}$ ratio and heat treatment BET-surface values up to $450 \mathrm{~m}^{2} \mathrm{~g}^{-1}$ and a quite broad pore size distribution with pore sizes in the range between 10 and $60 \mathrm{~nm} .^{79}$ However with respect to pore size and pore size distribution our experiment showed slightly better results.

We realized the synthesis of silica-titania aerogels by immersing $\mathrm{TiCl}_{4}$ into water glass solutions. The Ti-Si ratio was adjusted by the amount of $\mathrm{TiCl}_{4}$ respectively water glass (see also Table TS4, ESI $\dagger$ ). The BET surface values vary, depending on the reaction conditions and $\mathrm{Ti}-\mathrm{Si}$ ratios and are in the range 71 and $954 \mathrm{~m}^{2} \mathrm{~g}^{-1}$.

By far the best result was obtained in case of a Si-Ti ratio of $5: 1$ without additional amount of propylene oxide $\left(954 \mathrm{~m}^{2}\right.$ $\mathrm{g}^{-1}$; HS_126). Among the synthesized silica-titania aerogels this sample showed also the smoothest surface (see SEM image HS_126 Fig. 6e). Anyway, if in this procedure the alkaline compound $\mathrm{NaOH}$ is replaced by propylene oxide the surface area was reduced by more than 40\% (HS_91, $555 \mathrm{~m}^{2}$ $\left.\mathrm{g}^{-1}\right)$. Poor results were obtained if the Si-Ti ratio was adjusted to 10 (HS_43.1). The aerogel showed a very low BET surface 

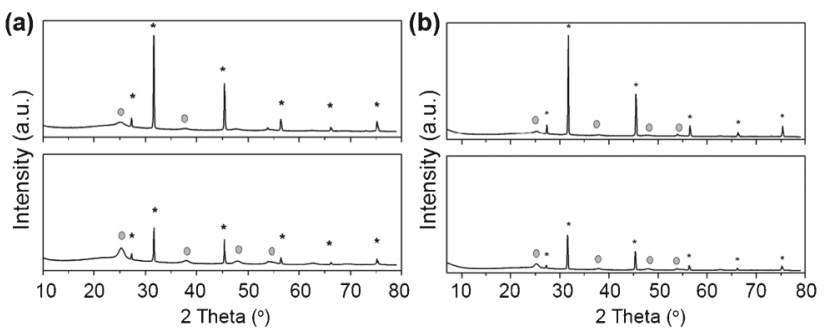

Fig. 7 (a) Powder diffraction pattern from silica-titania aerogel HS_115 as prepared (upper figure), respectively heat-treated (lower figure). Peaks corresponding to $\mathrm{NaCl}$ (JCPDS 01-077-2064) are marked with an asterisk. Peaks corresponding to tetragonal $\mathrm{TiO}_{2}$, anatase modification (JCPDS 004-0477) are marked with a sphere. (b) Powder diffraction pattern from silica-titania aerogel HS_126 as prepared (upper figure), respectively heat-treated (lower figure). Peaks corresponding to $\mathrm{NaCl}$ (JCPDS 01-077-2064) are marked with an asterisk. Peaks corresponding to tetragonal $\mathrm{TiO}_{2}$, anatase modification (JCPDS 004-0477) are marked with a sphere.

area $\left(71 \mathrm{~m}^{2} \mathrm{~g}^{-1}\right)$ and a very broad pore size distribution with pore sizes in the range $10-120 \mathrm{~nm}$ (see Fig. S9, ESI†), which is accompanied by a rough surface with pore sizes up to micrometer range (see SEM image in Fig. 6d). In contrary to the other mixed metal oxide aerogels, the aerogel network of this compound (HS_43.1) shows a more columnar structure. Interestingly within the series of mixed metal oxide aerogels only the titania-zirconia compound showed a narrow pore-size distribution (Fig. 6b). In case of the synthesized silica-titania aerogels the pore-size distribution was much broader with size intervals of 20-60 $\mathrm{nm}$ when propylene oxide as auxiliary agent was used (HS_91). The neutralization of an excess of acidic (HS_126) or alkaline (HS_43.1) precursors within the sol-gel reaction by $\mathrm{NaOH}$ (HS_126) or $\mathrm{HCl}$ (HS_43.1) obviously is responsible for wide pore size intervals ranging from 10-140 nm, respectively from 10-120 nm (HS_43.1). The crystallinity of all samples was checked by X-ray diffraction analyses - the results can be taken from Fig. 6f, $\mathrm{g}$ and 7, and S11-S14, ESI†. Although we performed many experiments no gel formation was observed starting from mixtures of $\mathrm{TiCl}_{4}-\mathrm{SiCl}_{4}$ and $\mathrm{TiCl}_{4}-$ $\mathrm{SiMeCl}_{3}$.

Most of the synthesized silica-titania aerogels do not crystallize, neither at room temperature - nor at elevated temperature $\left(450{ }^{\circ} \mathrm{C}\right)$. This finding coincides with the results from other groups. Schubert et al. obtained within the silicatitania system a very high onset temperature for the crystallization of anatase $\left(800{ }^{\circ} \mathrm{C}\right)$ respectively cristobalite $\left(1050{ }^{\circ} \mathrm{C}\right) .^{75}$ Especially for the heat treated samples of HS_115 and HS_126 onset of crystallisation can be derived from peaks on the position typical for anatase type $\mathrm{TiO}_{2}$ (see Fig. 7). Why theses samples show some kind of crystallisation whereas similar performed syntheses do not lead to crystalline products remains, however unclear.

Hydrolysis of mixtures of $\mathrm{Si}$ - and Ti-alkoxides or single source alkoxy precursors were used by other groups in order to prepare silica-titania aerogels and xerogels. Organic based single source precursors for silica-titania aerogels and xerogels were developed. ${ }^{75}$ This procedure is hardly suitable for mass production of this material because of the expected high costs of the precursors. In addition the BET surface areas were, depending on the single source precursor used, 90 respectively $230 \mathrm{~m}^{2} \mathrm{~g}^{-1}$. Also the stepwise hydrolysis of separated $\mathrm{Si}$ and $\mathrm{Ti}$ precursors did not lead to convincing results in view of quite low BET surface areas and relatively high costs caused by the precursors. ${ }^{73}$ Yoda et al. generated silica-titania mixed aerogels by impregnation of organic titanium precursors into silica gels using different techniques. $^{74,104,105}$ In terms of microstructure and porosity the results were brilliant. Large surface areas up to $900 \mathrm{~m}^{2} \mathrm{~g}^{-1}$ could be achieved ${ }^{74,104,105}$ and densities down to $0.15 \mathrm{~g}$ $\mathrm{cm}^{-13,105}$ were reached. On the other hand the procedures do not seem to be straightforward ${ }^{65}$ and in addition partially expensive and toxic precursors like tetramethoxysilane TMOS were used. ${ }^{105}$

\section{Conclusions}

We have reported a rapid, straightforward synthesis of high quality, highly stable aerogels based on hydrolysis reactions of cheap precursors comprising titanium(Iv) chloride, silicium(Iv) chloride, zirconium(IV) chloride with or without water glass as additional network former. It should be noted that cheap propylene oxide can also be used as auxiliary agent. Apart from single metal oxide aerogels mixed-metal-oxide aerogels can be prepared by the hydrolysis of a mixture of chloride precursors. This technique provides a straightforward method for the preparation of homogeneous gels in aqueous solutions without the need for alkoxide precursors or complicate reaction procedures. Ethanol, required for solvent exchange was recycled and this step did not complicate the procedure. Supercritical drying of some of the gels led to crackfree aerogel bodies with nanoporous structure showing narrow pore size distribution with pore sizes in the nm range. X-ray powder diffraction analysis show that the as-prepared aerogels did not crystallize. After heat treatment at $450{ }^{\circ} \mathrm{C}$ titania and zirconia aerogels and some of the mixed oxide aerogels crystallize to form expected crystal structures. With nitrogen adsorption measurements, the BET surface areas of the aerogels up to $1400 \mathrm{~m}^{2} \mathrm{~g}^{-1}$ were determined, suggesting their potential use as an additives in foundry applications. For the use as aerogelic binders, aerogel granules, foundry sand and as thermal insulating compounds in vehicles, pipelines, packaging and home building the production costs have to be reduced drastically. The materials prepared by this method are currently being evaluated for these purposes and the results will be published elsewhere.

\section{Acknowledgements}

The authors thank Markus Haases group for performing the XRD measurements and Martin Steinharts group for giving the possibility to perform a part of the experiments in his labs. 


\section{References}

1 H. D. Gesseashr and P. C. Goswami, Chem. Rev., 1998, 89, 765.

2 N. Hüsing and U. Schubert, Angew. Chem., Int. Ed., 1998, 37, 22.

3 A. C. Pierre and G. M. Pajonk, Chem. Rev., 2002, 102, 4243.

4 K. Sinko, Materials, 2010, 3, 704.

5 J. L. Gurav, I.-K. Jung, H.-Ho. Park, E. S. Kang and D. Y. Nadargi, J. Nanomater., 2010, DOI: 10.1155/2010/ 409310.

6 S. S. Kistler, Nature, 1931, 127, 741.

7 T. Sumiyoshi, I. Adachi, R. Enomoto, T. Iijima, R. Suda, N. Yokoyama and H. Yokogawa, Proceedings of the Fifth International Symposium on Aerogels (ISA 5), J. Non-Cryst. Solids, 1998, 225, 369.

8 T. Sumiyoshi, I. Adachi, R. Enomoto, T. Iijima, R. Suda, C. Leonidopoulos, D. R. Marlow, E. Prebys, R. Kawabata, H. Kawai, T. Ooba, M. Nanao, K. Suzuki, S. Ogawa, A. Murakami and M. H. R. Khan, Nucl. Instrum. Methods Phys. Res., Sect. A, 1999, 433, 385.

9 A. R. Buzykaev, A. F. Danilyuk, S. F. Ganzhur, E. A. Kravchenko and A. P. Onuchin, Nucl. Instrum. Methods Phys. Res., Sect. A, 2000, 433, 396.

10 A. K. Gougas, D. Ilie, S. Ilie and V. Pojidaev, Nucl. Instrum. Methods Phys. Res., Sect. A, 2000, 421, 249.

11 T. M. Tillotson, W. E. Sunderland, I. M. Thomas and L. W. Hrubesh, J. Sol-Gel Sci. Technol., 1994, 1, 241.

12 C. M. Mo, Y. H. Li, Y. S. Liu, Y. Zhang and L. D. Zhang, J. Appl. Phys., 1998, 83, 4389.

13 B. B. Owens, S. Passerini and W. H. Smyrl, Electrochim. Acta, 1999, 45, 215.

14 J. W. Long, K. E. Swider, C. I. Merzbacher and D. R. Rolison, Langmuir, 1999, 15, 780.

15 G. M. Pajonk, Appl. Catal., 1991, 72, 217.

16 G. Matis, F. Juillet and S. Teichner, J. Bull. Soc. Chim. Fr., 1976, 1633.

17 F. Blanchard, B. Pommier, J. P. Reymond and S. J. Teichner, J. Mol. Catal., 1982, 17, 171.

18 B. E. Yoldas, M. J. Annen and M. J. Bostaph, Chem. Mater., 2000, 12, 2475.

19 D. Quenard, B. Chevalier, H. Sallee, F. Olive and D. Giraud, Rev. Metall. Cah. Inf. Tech., 1998, 95, 1149.

20 J. F. T. Conroy, B. Hosticka, S. C. Davis, A. N. Smith and P. M. Norris, Microscale Thermophys. Eng., 1999, 3, 199.

21 M. Gronauer and J. Fricke, Acustica, 1986, 59, 177.

22 L. C. Klein, Annu. Rev. Mater. Sci., 1985, 15, 227.

23 A. H. Boonstra and C. A. M. Mulder, J. Non-Cryst. Solids, 1988, 105, 201.

24 P. B. Wagh, R. Begag, G. M. Pajonk, A. V. Rao and D. Haranath, Mater. Chem. Phys., 1999, 57, 214.

25 S. Henning and L. Svensson, Phys. Scr., 1981, 23, 697.

26 M. Yamane, S. Inove and A. Yasumori, J. Non-Cryst. Solids, 1984, 63, 12.

27 L. B. Brown, A. M. Anderson and M. K. Carrol, J. Sol-Gel Sci. Technol., 2012, 62, 404.

28 D. A. Ward and E. I. Ko, Chem. Mater., 1993, 5, 956.

29 D. J. Suh and T.-J. Park, Chem. Mater., 2002, 14, 1452.

30 S. J. Teichner, G. A. Nicolaon, M. A. Vicarini and G. E. E. Gardes, Adv. Colloid Interface Sci., 1976, 5, 245.
31 C. Stocker and A. Baiker, J. Non-Cryst. Solids, 1998, 223, 165.

32 L. K. Campbell, B. K. Na and E. I. Ko, Chem. Mater., 1992, 4, 1329.

33 H. Li, S. G. Sunol and A. K. Sunol, Nanotechnology, 2012, 23, 294012.

34 S. Kelly, F. H. Pollak and M. Tomkiewicz, J. Phys. Chem. B, 1997, 101, 2730.

35 B. Ksapabutr, E. Gulari and S. Wongkasemjit, Mater. Sci. Forum Vols., 2005, 549, 480.

36 C. N. Chervin, B. J. Clapsaddle, H. W. Chiu, A. E. Gash, J. H. Jr. Satcher and S. M. Kauzlarich, Chem. Mater., 2005, 17, 3345 .

37 T. Okubo, T. Takahashi, M. Sadakata and H. Nagamoto, J. Membr. Sci., 1996, 118(2), 151.

38 C. Xia, H. Cao, H. Wang, P. Yang, G. Meng and D. Peng, J. Membr. Sci., 1999, 162, 181.

39 S. D. Bhagat, Y.-H. Kim, M.-J. Moon, Y.-S. Ahn and J.G. Ye, Solid State Sci., 2007, 9(7), 628.

40 L. W. Hrubesh and R. W. Pekala, J. Mater. Res., 1994, 9(3), 731.

41 N. Olivi-Tran, A. Lecomte, P. Lenormand and A. Dauger, J. Phys.: Condens. Matter, 2000, 12, 7547.

42 Z. Zhao, D. Chen and X. Jiao, J. Phys. Chem. C, 2007, 111, 18738.

43 A. E. Gash, T. M. Tillotson, J. H. Jr. Satcher, L. W. Hrubesh and R. L. Simpson, J. Non-Cryst. Solids, 2001, 285, 22.

44 A. E. Gash, J. H. Satcher and R. L. Simson, Chem. Mater., 2003, 15, 3268.

45 A. E. Gash, T. M. Tillotson, J. H. Jr. Satcher, J. F. Poco, L. W. Hrubesh and R. L. Simpson, Chem. Mater., 2001, 13, 999.

46 B. J. Clapsaddle, A. E. Gash, J. H. Satcher and R. L. Simpson, J. Non-Cryst. Solids, 2003, 331(1-3), 190.

47 Y. P. Gao, C. N. Sisk and L. J. Hope-Weeks, Chem. Mater., 2007, 19, 6007.

48 S. K. Gill and L. J. Hope-Weeks, Chem. Commun., 2009, 4384-4386.

49 Z. Deng, J. Wang, Y. Zhang, Z. Weng, Z. Zhang, B. Zhou, J. Shen and L. Cheng, Nanostruct. Mater., 1999, 11(8), 1313.

50 R. Takahashi, S. Sato, T. Sodesawa, K. Suzuki, M. Tafu, K. Nakanishi and N. Soga, J. Am. Ceram. Soc., 2001, 84(9), 1968.

51 R. Takahashi, K. Nakanishi and N. Soga, J. Sol-Gel Sci. Technol., 1997, 8, 71.

52 R. Takahashi, K. Nakanishi and N. Soga, J. Ceram. Soc. Jpn., 1998, 106, 772.

53 H. Schäfer, H.-R. Stock and P. Mayr, Corros. Sci., 2005, 47, 953.

54 C. C. Pavel, D. Vuono, L. Catanzaro, P. De Luca, N. Bilba, A. Nastro and J. B. Nagy, Microporous Mesoporous Mater., 2002, 56, 227.

55 D. S. van Vuuren, S. J. Oosthuizen and M. D. Heydenrych, The Journal of The Southern African Institute of Mining and Metallurgy, 2011, 111, 141.

56 R. A. Gonzalez, C. D. Musick and J. N. Tilton, Process for controlling agglomeration in the manufacture of $\mathrm{TiO}_{2}$, U.S. Patent 5,508,015, April 16, 1996.

57 J. C. Deberry, M. Robinson, M. D. Pomponi, A. J. Beach, Y. Xiong and K. Akhtar, Controlled vapor phase oxidation 
of titanium tetrachloride to manufacture titanium dioxide, U.S. Patent 6,387,347, May 14, 2002.

58 Suplier: Hutong Global Co., Ltd, Chagugang town,wuqing district,Tianjin,China. Date of quotation: 09/17/2012.

59 Suplier: Tomson Chemical Limited, Hangzhou, China, Price: 8400 \$/ton; Date of quotation: 09/17/2012.

60 T.-H. Wang, A. M. N. Lopez, S. Li, D. A. Dixon and J. L. Gole, J. Phys. Chem. A, 2010, 114, 7561.

61 W. Zheng, X. Liu, Z. Yan and L. Zhu, ACS Nano, 2009, 3(1), 115.

62 A. D. Paola, M. Bellardita, R. Ceccato, L. Palmisano and F. Parrino, J. Phys. Chem. C, 2009, 113, 15166.

63 D.-S. Lee and T.-K. Liu, J. Sol-Gel Sci. Technol., 2002, 25, 121.

64 N. Sasireka, B. Rajesh and Y.-W. Chen, Thin Solid Films, 2009, 518(1), 43.

65 Producer: Shanghai Richem International Co., Ltd., Shanghai, China, Date of quotation: 09/17/2012.

66 F. J. Broecker, W. Heckmann, F. Fischer, M. Mielke, J. Schroeder and A. Stange, Proceedings of the Second International Symposium on Aerogels (ISA2), Rev. Phys. Appl. Colloq., 1989, 10.

67 R. A. Boyse and E. I. Ko, Catal. Lett., 1996, 38, 225.

68 L. Chen, J. Hu and R. M. Richards, ChemPhysChem, 2008, 9, 1069.

69 H. W. Brinkmann, G. Z. Zhao and A. Burggraf, J. Solid State Ion, 1993, 37, 63.

70 A. Rahtu and M. Ritala, J. Mater. Chem., 2002, 12, 1484.

71 A. K. Kivi, E.-L. Lakomaa, A. Root, H. Osterholm, J.P. Jacobs and H. H. Brongersma, Langmuir, 1997, 13, 2717.

72 J. C. Wang, S. H. Chiao, C. L. Lee, T. F. Lei and Y. M. Lin, J. Appl. Phys., 2002, 92, 3936.

73 M. A. Holland, D. M. Pickup, G. Mountjoy, E. S. C. Tsang, G. W. Wallidge, R. J. Newport and M. E. Smith, J. Mater. Chem., 2000, 10, 2495.

74 S. Yoda, K. Otake, Y. Takebayashi, T. Sugeta and T. Sato, J. Non-Cryst. Solids, 2001, 285, 8.

75 W. Rüpp, N. Hüsing and U. Schubert, J. Mater. Chem., 2002, 12, 2594.

76 K. W. Terry and T. D. Tilley, Chem. Mater., 1991, 3, 1001.

77 M. P. Coles, C. G. Lugmair, K. W. Terry and T. D. Tilley, Chem. Mater., 2000, 12, 122.

78 X. M. Wang and P. Xia, J. Mater. Res., 2006, 21(2), 355.

79 Y. Wan, J. X. Ma, W. Zhou, Y. J. Zhu, X. Y. Song and H. X. Li, Appl. Cat. A: General, 2004, 277(55), 1.

80 B. Malinowska, J. Walendziewski, D. Robert, J. V. Weber and M. Storalski, Int. J. Photoenergy, 2003, 5, 147.
81 B. Sen and A. Vannice, J. Catal., 1998, 113, 52.

82 D. Robert and J. V. Weber, J. Clean. Prod., 1998, 6, 335.

83 G. Poelz and R. Riethmuller, Cerenkov counters, Report 811055, DESY (Deutches Elektronen-Synchrotron), 1981.

84 A. V. Rao, G. M. Pajonk and N. N. Parvathy, J. Mater. Sci., 1994, 29, 1807.

85 S. Ki. Hong, Mi. Y. Yoon and H. Jin Hwang, J. Am. Ceram. Soc., 2011, 94(10), 3198.

86 Qingdao Sinoglory Chemical Co., Ltd, Qingdao, China.

87 Y. C. Cha, C. E. Kim, S. Lee, H. J. Hwang, J. W. Moon, I. S. Han and S.-K. Woo, Sol. State Phenom. Vols., 2007, 671, 124.

88 A. V. Rao, A. P. Rao and M. M. Kulkarni, J. Non-Cryst. Solids, 2004, 350, 224.

89 C. J. Lee, G. S. Kim and S. H. Hyun, J. Mater. Sci., 2002, 37, 2237.

90 L. M. Hair, R. W. Pekala, R. E. Stone, C. Chen and S. L. Buckley, J. Vac. Sci. Technol., A, 1988, 6, 2559.

91 C. A. Garcia-Gonzalez, M. C. Camino-Rey, M. Alnaief, C. Zetzl and I. Smirnova, J. Supercrit. Fluids, 2012, 66, 297.

92 F. Schwertfeger, D. Frank and M. Schmidt, J. Non-Cryst. Solids, 1998, 225, 24.

93 FeyeCon Development \& Implementation B. V. 1382 GS Weesp, The Netherlands.

94 C. Liang, G. Sha and S. Guo, J. Non-Cryst. Solids, 2000, 271, 167.

95 F. Kirkbir, H. Murata, D. Meyers and S. R. Chaudhuri, J. Non-Cryst. Solids, 1998, 225, 14.

96 T. M. Tillotson, W. E. Sunderland, I. M. Thomas and L. W. Hrubesh, J. Sol-Gel Sci. Technol., 1994, 1, 241.

97 Dongying Longxing Chemical Co., Ltd., Shandong, China, Date of quotation: 10/08/2012.

98 G. B. Kolesar, W. H. Siddiqui, R. G. Geil, R. M. Malczewski and E. J. Hobbs, Fundam. Appl. Toxicol., 1989, 13, 285.

99 H. Tamon, T. Kitamura and M. Okazaki, J. Colloid Interface Sci., 1998, 197, 353.

100 B. Xia, H. Huang and Y. Xie, Mater. Sci. Eng., B, 1999, 57, 150.

101 B. M. Gauthier, S. D. Bakrania, A. M. Anderson and M. K. Carroll, J. Non-Cryst. Solids, 2004, 350, 238.

102 X. Z. Guo, L. Q. Yan, H. Yang, J. Li, C. Y. Li and X. B. Cai, Acta. Phys. Chim. Sin., 2011, 27(10), 2478.

103 C. Stöcker, M. Schneider and A. Baiker, J. Porous Mater., 1996, 2, 325.

104 S. Yoda, Y. Tasaka, K. Uchida, A. Kawai, S. Ohshima and F. Ikazaki, J. Non-Cryst. Solids, 1998, 225, 105.

105 S. Yda, K. Ohtake, Y. Takebayashi, T. Sugeta, T. Sako and T. Sato, J. Mater. Chem., 2000, 10, 2151. 